\title{
Measuring Mass Attenuation Coefficient and Elemental Composition for Egbeda Soil Series of Southwestern Nigeria
}

\author{
${ }^{1 *}$ Fajemiroye, Joseph Ademola, ${ }^{2}$ Adejumo, Oladipo Olukunle and ${ }^{3}$ Balogun, Fatai Olabanji \\ ${ }^{1}$ Department of Physics, The Polytechnic, Ibadan, Nigeria. \\ ${ }^{2}$ Department of Physics and Solar Energy, Bowen University, Iwo, Nigeria \\ ${ }^{3}$ Department of Earth Sciences, University of Oregon, Eugene, Oregon, 97403, USA
}

\begin{abstract}
Information from workers on the profitability of cassava on Iwo and Egbeda soil series in Oyo state, Nigeriahave shown the Iwo soil series to be more profitable given the same scale of cassava cultivation. Therefore the need arises to improve on the soil properties of Egbeda soil series which will possibly improve the production efficiency for this category of farmers. In this work, an experimental procedure using gamma attenuation technique to determine the mass attenuation coefficient at different gamma ray energies of $59.5,661.7,1173.2$ and $1332.5 \mathrm{keV}$, and at depths of $0-15,15-30,30-45,45-60,60-75$ and $75-90 \mathrm{~cm}$ into the Egbeda soil series profile have been studied. Likewise X-ray fluorescence, XRF, method was used to obtain the elemental composition and concentrations at these depths while the XCOM software was applied to obtain the photon mass attenuation coefficients at the different gamma ray energies for the depths .Mass attenuation coefficients, $\mu_{s}$ obtained experimentally and that computed theoretically using XCOM varied exponentially with photon energy. The correlation coefficient between the experimentally-obtained and XCOM-obtained $\mu_{\mathrm{s}}$ for the energies considered ranged from $0.89-0.96$. The variation of $\mu_{s}$ with soildepth show that the top soil $(0-15 \mathrm{~cm}$ depths $)$ is least attenuating with gamma ray penetrability varying down the profile. Information on the mass attenuation coefficients, elemental composition, and concentrations at varying depths into the soil profile will go a long way in contributing to efforts at improving the soil condition of the Egbeda soil series.
\end{abstract}

Keywords: Egbeda soil series; Gamma attenuation technique; Gamma ray energies; Mass attenuation coefficient; X-ray fluorescence; XCOM.

\section{Introduction}

Any serious attempt to judiciously use land for agricultural, regional, or urban development must start with a consideration of the nature and kind of the soil series existing at a region and its ability to support high yield of crops (Abegunde et. al., 2017). In southwest Nigeria, up to forty-two (42) soil series are recognized with major groupings into eight soil associations of Iwo, Ondo, Egbeda, Itagunmodi, Okemessi, Mamu, Jago and Origo soil associations. Each of these soil associations have different soil series members distributed in different quantities (or spread) within the southwestern region of Nigeria. Under Egbeda soil association we have Egbeda, Makun and Olorunda soil series (Smyth and Montgomerry, 1962).

Abegunde, et al. in 2017 opined that the farmers who planted cassava/maize on Iwo soil series operating on 1.05 hectare of land earned more profit than their counterparts who planted on Egbeda soil series in terms of the net farm income between total revenue and total cost. The Iwo soil series was discovered to be more profitable given the same scale of cassava/maize cultivation compared to the Egbeda soil series. A major reason behind the poor performance of the Egbeda soil series for cassava/maize production could be due to its structural composition which needs to be investigated from different perspectives. Information on the attenuation coefficient derived from the elemental composition of the Egbeda soil series will lead to obtaining necessary measures required to improving its usage. Information from the measurement of the 
mass attenuation coefficient at varying depths into the soil profile for Egbeda soil series of southwest Nigeria will be useful in the planning of all aspects of agricultural development.

Individual Nigerian farmers and the extension services division of the Ministries of Agriculture and Natural Resources stand in urgent need of more specific information about the suitability of various soils for certain crop types. This specific information is also utilized by highway and drainage engineers, estate developers, builders of factories and manufacturing plants, and by companies and organizations that require land for intensive campaigns (Adejumo, 2009). The variability of the mass attenuation coefficient at varying depths into the soil profile for Egbeda soil series in conjunction with other studies about the nature and properties of this soil series will give more insight on the water and nutrient retention ability of this soil series.

Information on the elemental composition and concentration at varying depths into the soil profile will go a long way in contributing to efforts at improving the soil condition of the Egbeda soil series. This will no doubt improve the production efficiency of the Egbeda soil series for farmers of southwest Nigeria. In this work, the authors developed an experimental procedure using gamma ray spectrometric technique to determine the mass attenuation coefficient at different gamma ray energies at depths of $0-15,15-30,30-$ 45, $45-60,60-75$ and $75-90 \mathrm{~cm}$ into the Egbeda soil series profile. X-ray fluorescence, XRF, method was used to obtain the elemental composition and concentration at these depths and the XCOM computer software database was applied to obtain the photon mass attenuation coefficients at the different gamma ray energies at the varying depths of interest mentioned above.

\section{Materials and Method}

\subsection{Mathematical Background}

For a parallel, mono-energetic beam of X- or $\gamma$-rays, the distribution of transmitted radiation through a medium is a function of the absorption characteristics defined by the Lambert-Beer's law (Pourimani, et. al., 2020) as:

$$
I=I_{0} \exp \left(-\mu_{\lambda} x\right)
$$

where $I$ is the transmitted radiation intensity, $I_{0}$ is the incident electromagnetic radiation intensity, $\mu_{\lambda}$ is the linear attenuation coefficient, with the subscript $\lambda$, wavelength of the radiation.

For an absorber that is solid, and denoting the mass absorption coefficient, $\mu$ as the ratio of linear attenuation coefficient and density, the Lambert-Beer's equation becomes:

$$
I=I_{0} \exp \left(-\mu_{s} \rho_{s} x\right)
$$

where $\mu$ and $\rho$ denote the mass attenuation coefficient and density respectively, the subscript $s$ referring to soil, and $x$ represents the thickness of the absorber.

Because radiation intensity is proportional to the number of gamma-ray quanta $\mathrm{N}$, equation 2 can be rewritten as (Pires, et. al., 2006):

$$
\begin{aligned}
N & =N_{0} \exp \left(-\mu_{s} \rho_{s} x\right) \\
\text { or } \ln \frac{N}{N_{0}} & =-\left(\mu_{s} \rho_{s} x\right)
\end{aligned}
$$

and, $\mu_{s}=-\frac{1}{\rho_{s} x} \ln \frac{N}{N_{0}}$

From equation 3, the mass attenuation coefficients for the different depths of the Egbeda soil series may be computed.

\subsection{Soil sample collection and pretreatment}

A typical Egbeda soil series is located at the Parry road Agronomy farm of the University of Ibadan, UI, Central southwest, Nigeria $\left(7.4443^{\circ} \mathrm{N}, 3.8995^{\circ} \mathrm{E}\right)$. At this site, a soil test pit 50 x 100 and $120 \mathrm{~cm}$ depth was dug. Using a linen tape, with reading accuracy, $0.1 \mathrm{~cm}$, depths of $0-15 \mathrm{~cm}, 15-30 \mathrm{~cm}, 30-45 \mathrm{~cm}, 45-$ $60 \mathrm{~cm}, 60-75 \mathrm{~cm}$ and $75-90 \mathrm{~cm}$ were marked. Using cylindrical metal containers driven in one continuous motion into the soil profile, undisturbed soil core samples were collected at these different depths stated 
above. Each of the cylindrical containers has a diameter of $5.6 \mathrm{~cm}$ and thickness, $x$ of $5.2 \mathrm{~cm}$. These samples were taken to the Material Science Laboratory of the Department of Geology, The Polytechnic, Ibadan, Nigeria for preparation. The samples were oven-dried in Heatbird ${ }^{\mathrm{TM}}$ stainless steel oven model no 0357 (operating between $100{ }^{\circ} \mathrm{C}$ to $450{ }^{\circ} \mathrm{C}$ ) at $105^{\circ} \mathrm{C}$ for 24 hours (Hillel, 1998) to remove the water content of the soil sample. The masses of the soil samples were observed at 2-hour intervals until a constant mass was attained for the dried soil sample. These dried samples were then taken to the Physics Laboratory of the University of Ibadan, Nigeria for gamma-ray spectrometric counting. After this, the samples were taken to the centre for energy research and development, CERD, Obafemi Awolowo University, OAU, Ile- Ife, Nigeria for X-Ray Fluorescence, XRF analysis of the soil samples.

\subsection{Gamma-Ray Spectrometer arrangement and Experiment}

The gamma-ray spectrometer was arranged in such a way that the $76 \mathrm{~mm} \times 76 \mathrm{~mm} \mathrm{NaI}$ (Tl) detector crystal, model 802 series was coupled to a CANBERRA ${ }^{\mathrm{TM}}$ manufactured multichannel analyser, MCA, model 1104, through a preamplifier as shown in figure 1. The MCA consists of an analogue to digital converter, ADC, control logic, CL unit, an internal amplifier, an Einhell 30 high voltage power supply, HVPS unit and a screen display, SD unit. A rechargeable lead-acid $12 \mathrm{~V}$ battery unit was connected to the HVPS as shown in Fig 1.

\subsection{Experiment}

The source number ENV984084 supplied by the International Atomic Energy Agency, IAEA and some standard radionuclides from Nucleus Inc, Oak Ridge, TN, USA were used as the gamma-ray sources.

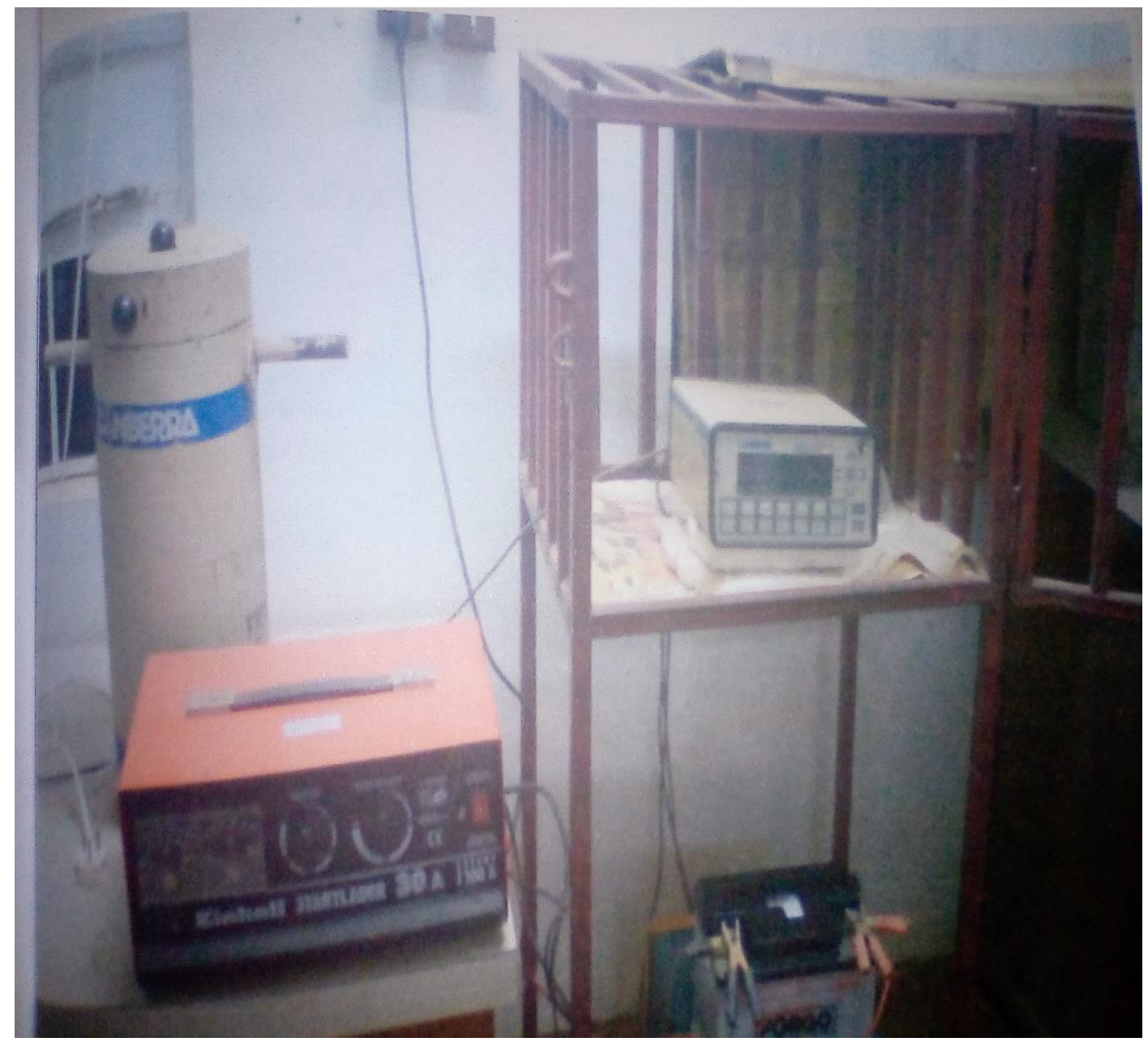

Fig. 1. Gamma-ray Spectrometer arrangement.

\subsection{Detector Calibration}

The set-up used in this work was calibrated for energy-channel number linearity and detector counts disintegration rate linearity. 


\subsubsection{Energy Calibration}

The source number ENV984084 supplied by the International Atomic Energy Agency, IAEA and some standard radionuclides from Nucleus Inc, Oak Ridge, TN, USA was used as the gamma-ray source for energy calibration, and these radionuclides were chosen because the calibration energies obtainable from it will cover the entire range of energies over which measurements are to be made. The source was placed at a distance reasonably close to the

detector and suitable for the geometry conditions used in the experiment. The spectrum was measured for 3,600 seconds, and the peaks which correspond to the following energies were used: $2614.4,1764.5,1460.8$, $1332.5,1274.5,1173.2,661.7$ and $511 \mathrm{keV}$. These energies correspond to the channel numbers $125,78,60$, 50, 48, 42, 18 and 12 respectively. From the energy/channel plot, a linear graph was obtained which gave the energy/channel relationship as:

$$
E(\mathrm{MeV})=1.83 \times 10^{-2} N+0.3585
$$

where $\mathrm{N}$ is the channel number

The peak areas used to determine the numbers of gamma photons $\mathrm{N}$ were derived from manually set regions-of-interest, ROI, hence there was no need for a peak width calibration.

\subsubsection{Efficiency Calibration}

The absolute full-energy peak efficiency calibration in this work was carried out using the reference standard source number ENV984084 supplied by the International Atomic Energy Agency, IAEA. The reference source is certified to have activity concentration of $479.15 \pm 23.43 \mathrm{~Bq} \mathrm{Kg}^{-1}, 566.47 \pm 8.33$ $\mathrm{Bq} \mathrm{Kg}{ }^{-1}$ and $11.60 \pm 0.77 \mathrm{~Bq} \mathrm{Kg}{ }^{-1}$ for ${ }^{40} \mathrm{~K},{ }^{238} \mathrm{U}$ and ${ }^{232} \mathrm{Th}$ respectively.

Relating the computed net area, A under the photopeak above the background to the activity concentration, $\mathrm{C}$ of the reference source using the relation due to Nordin (1999):

$$
E(p)=\frac{A}{t C Y m}
$$

where $E(p)$ is the detector absolute full-energy peak efficiency of the radionuclide

$t$ is the counting time, $Y$ is the gamma yield, which is the fraction of the $\gamma$-rays of a particular energy per disintegration and $m$ is the mass of the sample.

We obtained the detection efficiencies for the three radionuclides ${ }^{40} K,{ }^{238} U$ and ${ }^{232} T h$ as $0.0163,0.0144$ and 0.00956, respectively. The error in the efficiency was calculated following the relation in Knoll (1989):

$$
\delta E_{p}=E_{p}\left[\left(\delta_{A} / A\right)^{2}+\left(\delta_{c} / C\right)^{2}\right]^{1 / 2}
$$

where $\delta E_{p}$ is the error in the value of the efficiency, $E_{p}$

$\delta_{A}$ is the error in the net count

and $\delta_{c}$ is the error in the activity concentration, $\mathrm{C}$

After computation, the detection efficiencies for the three radionuclides ${ }^{40} K,{ }^{238} U$ and ${ }^{232} T h$ become 0.0163 $\pm 0.00079,0.0144 \pm 0.000218$ and $0.00956 \pm 0.000128$, respectively.

The graph of Detection efficiency against energy is shown in Fig. 2. 


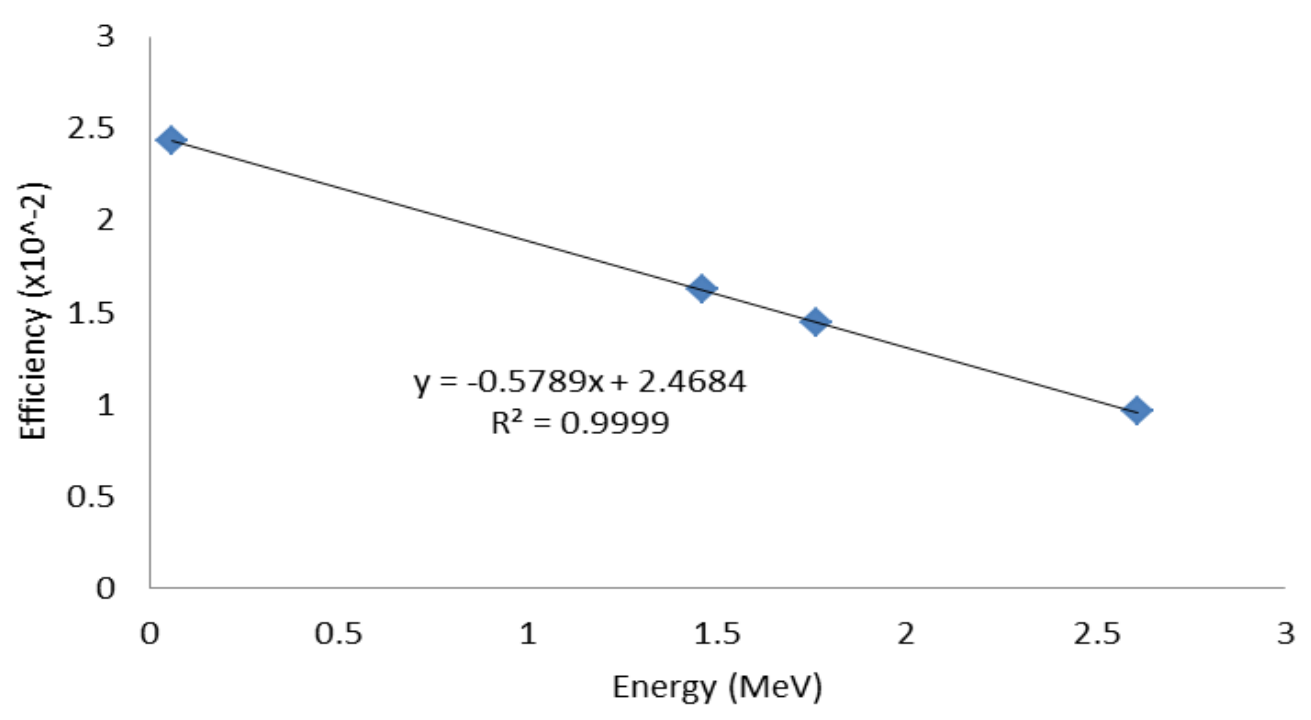

Fig. 2: Graph of Detection Efficiency against Energy

By extrapolation, we obtained the detection efficiencies at the energies of interest in this work.

\subsubsection{Radiological Data Acquisition}

The source was placed over a collimated lead shield which was in turn placed over the soil sample. The HVPS unit was set at $0.75 \mathrm{kV}$. On the amplifier unit, the coarse gain was set at 10, the fine gain at 4.7 and the shaping time at $2 \mu \mathrm{s}$. For the data acquisition setup, the full memory was set at $4 \mathrm{~K}$ and the livetime was preset at 10,800 seconds (10 hours) in order to reduce statistical fluctuation in data acquisition. The spectrum display was observed on the display unit of the MCA of the Gamma Spectrometry laboratory at the Physics Department of the University of Ibadan, Nigeria. Data was accumulated with the soil sample and without the soil as absorber. From the acquired spectra, the number of gamma-ray photons, $\mathrm{N}$ was determined. Following the discussions in the section on the mathematical background, the mass attenuation coefficients for the Egbeda soil series at varying soil depths were determined.

\subsubsection{Presentation of Raw Data}

The thickness of the cylindrical soil sample container was used as the parameter $\mathrm{x}$ of equation 3 . Table 1 shows the data for the Egbeda soil series taken on $3^{\text {rd }}$ September, 2013 and calculation for the mass attenuation coefficients. The mass attenuation coefficients for the dried soil sample, $\mu_{s}$ at the depths of interest, and at different gamma-ray energies were determined using equation 3, and displayed in Table 1 . The dried soil samples were removed from the metal sample container before the radiological data acquisition process, hence, there was no need to take the attenuation of gamma-rays by the metal sample container into consideration.

\subsubsection{X-Ray Fluorescence (XRF) Analysis of Soil Samples and NIST XCOM Program}

The elemental analysis of the collected soil samples at the different depths earlier mentioned was carried out using the facilities of the energy dispersive X-ray fluorescence, EDXRF, spectrometer at the centre for energy research and development (CERD), OAU, Ile-Ife. In carrying out this analysis, the collected samples were first ground in a mortar with pestle to fine powder and then put inside a pelletizer ring. Using a Carver Inc. manufactured hydraulic press at $8-10 \mathrm{kgf}$, the samples were turned into cylindrical pellets and then kept inside polythene bags ready for transfer into the sample chamber of the two-dimensional, (2D), EDXRF spectrometer. For this spectrometer, the X-ray optical path is in one plane (2 dimensions); the X-ray tube source irradiates the sample directly, and the fluorescence coming from the sample was measured by energy dispersive XR-100CR AMPTEK ${ }^{\mathrm{TM}}$ manufactured silicon X-ray detector directly. The qualitative (elemental composition) and quantitative (concentrations of the elements present) analyses of the collected soil samples were determined, and the result obtained is presented in Table 2. The percentage concentration values (derived from the quantitative analyses done with EDXRF) of elements present in each of the soil depth of 
interest were inserted into the XCOM software (a web program generated by the United States of America, USA based National Institute of Standards and Technology, NIST, which calculates the photon cross sections for scattering, photoelectric absorption, and pair production, generating the total photon attenuation coefficients by any element, compound or mixture at various photon energies) to generate the mass attenuation coefficients for each soil depth of interest for the Egbeda soil series, and the result presented in Table 3.

\section{Result and analysis}

Table 1: Attenuation Coefficient of Egbeda Soil Type at Varying Depths into the Profile

\begin{tabular}{|c|c|c|c|c|c|c|c|c|c|c|}
\hline \multicolumn{11}{|c|}{ Soil sample collected on 3rd September 2013} \\
\hline \multicolumn{11}{|c|}{ Thickness of dry soil sample, $x=5.2 \mathrm{~cm}$} \\
\hline \multicolumn{4}{|c|}{ Volume of dry soil sample, $V_{s}=\pi r^{2} x=3.14$} & $\left(\frac{5.6}{2}\right)$ & $(5.2)=$ & 128.01 & & & & \\
\hline \multirow{4}{*}{$\begin{array}{l}\text { Soil } \\
\text { Depth } \\
(\mathrm{cm})\end{array}$} & \multirow{4}{*}{$\begin{array}{l}\text { Mass of } \\
\text { Dried } \\
\text { Soil }(g)\end{array}$} & \multirow{4}{*}{$\begin{array}{l}\text { Bulk Density of Soil } \\
\rho_{s}=\frac{\text { mass of dry soil }}{\text { vol. of dry soil }}\end{array}$} & \multicolumn{8}{|c|}{ Number of Counts at Different Gamma-Ray Energies } \\
\hline & & & \multicolumn{4}{|c|}{ With Soil Absorber, $N$} & \multicolumn{4}{|c|}{ Without Soil Absorber, $N_{0}$} \\
\hline & & & \multicolumn{4}{|c|}{ Energies in $\mathrm{keV}$} & \multicolumn{4}{|c|}{ Energies in $\mathrm{keV}$} \\
\hline & & & 59.5 & 661.7 & $\begin{array}{l}1173 . \\
2\end{array}$ & 1332.5 & 59.5 & 661.7 & 1173.2 & 1332.5 \\
\hline $0-15$ & 133.3 & 1.44 & $\begin{array}{l}1672 \\
\pm 5.2\end{array}$ & $\begin{array}{l}5111 \\
\pm 6.2\end{array}$ & $\begin{array}{l}20763 \\
\pm 4.6\end{array}$ & $\begin{array}{l}21688 \\
\pm 7.2\end{array}$ & $\begin{array}{l}3692 \\
\pm 5.2\end{array}$ & $\begin{array}{l}7112 \\
\pm 6.2\end{array}$ & $\begin{array}{l}26888 \\
\pm 4.6\end{array}$ & $\begin{array}{l}27624 \\
\pm 7.2\end{array}$ \\
\hline $15-30$ & 140.3 & 1.39 & $\begin{array}{l}1512 \\
\pm 4.2\end{array}$ & $\begin{array}{l}5009 \\
\pm 6.2\end{array}$ & $\begin{array}{l}20147 \\
\pm 4.6\end{array}$ & $\begin{array}{l}21718 \\
\pm 7.6\end{array}$ & $\begin{array}{l}3698 \\
\pm 4.2\end{array}$ & $\begin{array}{l}7119 \\
\pm 6.5\end{array}$ & $\begin{array}{l}26902 \\
\pm 4.8\end{array}$ & $\begin{array}{l}27648 \\
\pm 7.6\end{array}$ \\
\hline $30-45$ & 117.6 & 1.41 & $\begin{array}{l}1457 \\
\pm 4.8\end{array}$ & $\begin{array}{l}5164 \\
\pm 6.5\end{array}$ & $\begin{array}{l}20499 \\
\pm 4.2\end{array}$ & $\begin{array}{l}22293 \\
\pm 7.6\end{array}$ & $\begin{array}{l}3709 \\
\pm 4.2\end{array}$ & $\begin{array}{l}7126 \\
\pm 6.5\end{array}$ & $\begin{array}{l}26908 \\
\pm 4.6\end{array}$ & $\begin{array}{l}27714 \\
\pm 7.6\end{array}$ \\
\hline $45-60$ & 128.9 & 1.36 & $\begin{array}{l}1634 \\
\pm 4.2\end{array}$ & $\begin{array}{l}5282 \\
\pm 6.5\end{array}$ & $\begin{array}{l}21605 \\
\pm 4.8\end{array}$ & $\begin{array}{l}22689 \\
\pm 7.8\end{array}$ & $\begin{array}{l}3722 \\
\pm 4.8\end{array}$ & $\begin{array}{l}7134 \\
\pm 6.5\end{array}$ & $\begin{array}{l}26946 \\
\pm 4.2\end{array}$ & $\begin{array}{l}27744 \\
\pm 7.8\end{array}$ \\
\hline $60-75$ & 125.1 & 1.23 & $\begin{array}{l}1656 \\
\pm 4.8\end{array}$ & $\begin{array}{l}5163 \\
\pm 6.2\end{array}$ & $\begin{array}{l}21089 \\
\pm 4.8\end{array}$ & $\begin{array}{l}22245 \\
\pm 7.2\end{array}$ & $\begin{array}{l}3748 \\
\pm 4.8\end{array}$ & $\begin{array}{r}7148 \\
\pm 6.2\end{array}$ & $\begin{array}{l}26954 \\
\pm 4.8\end{array}$ & $\begin{array}{l}27768 \\
\pm 4.6\end{array}$ \\
\hline $75-90$ & 82.5 & 1.22 & $\begin{array}{r}1666 \\
\pm 5.2\end{array}$ & $\begin{array}{l}5200 \\
\pm 6.2\end{array}$ & $\begin{array}{l}21508 \\
\pm 4.6\end{array}$ & $\begin{array}{l}22745 \\
\pm \pm 4.2\end{array}$ & $\begin{array}{l}3766 \\
\pm 5.2\end{array}$ & $\begin{array}{r}7162 \\
\pm 6.2\end{array}$ & $\begin{array}{l}26962 \\
\pm 4.6\end{array}$ & $\begin{array}{l}27782 \\
\pm 4.6\end{array}$ \\
\hline \multicolumn{11}{|c|}{ Soil Attenuation Coefficient, $\mu_{s}=-\frac{1}{\rho_{s} x} \ln \frac{N}{N_{0}}$} \\
\hline & & & \multicolumn{2}{|c|}{$59.5 \mathrm{keV}$} & \multicolumn{2}{|c|}{$661.7 \mathrm{keV}$} & $1173.2 \mathrm{keV}$ & \multicolumn{3}{|c|}{$1332.5 \mathrm{keV}$} \\
\hline \multicolumn{2}{|l|}{$0-15$} & & \multicolumn{2}{|l|}{0.1057} & 0.0441 & \multicolumn{2}{|c|}{0.0345} & \multicolumn{2}{|c|}{0.0323} & \\
\hline \multicolumn{2}{|l|}{$15-30$} & & \multicolumn{2}{|l|}{0.1234} & 0.0485 & \multicolumn{2}{|c|}{0.0399} & \multicolumn{2}{|c|}{0.0333} & \\
\hline \multicolumn{2}{|l|}{$30-45$} & & \multicolumn{2}{|l|}{0.1271} & 0.0438 & \multicolumn{2}{|c|}{0.0370} & \multicolumn{2}{|c|}{0.0296} & \\
\hline \multicolumn{2}{|l|}{$45-60$} & & \multicolumn{2}{|l|}{0.1167} & 0.0426 & 0.03 & & 0.0 & & \\
\hline $60-75$ & & & 0.1278 & & 0.0509 & 0.03 & & 0.0 & & \\
\hline $75-90$ & & & 0.1285 & & 0.0504 & 0.03 & & 0.0 & & \\
\hline
\end{tabular}

Table 2: Percentage concentration of elements present converted from ppm values

\begin{tabular}{|l|c|}
\hline & Elements \\
\hline
\end{tabular}




\begin{tabular}{|l|l|l|l|l|l|l|l|l|l|l|l|l|l|l|}
\hline \multirow{2}{*}{$\begin{array}{l}\text { Soil } \begin{array}{l}\text { Depth } \\
(\mathrm{cm})\end{array} \\
-15\end{array}$} & $\mathrm{~K}$ & $\mathrm{Ca}$ & $\mathrm{Fe}$ & $\mathrm{Ti}$ & $\mathrm{Mn}$ & $\mathrm{Ni}$ & $\mathrm{Cu}$ & $\mathrm{Zn}$ & $\mathrm{Sr}$ & $\mathrm{Zr}$ & $\mathrm{Se}$ & $\mathrm{V}$ \\
\cline { 2 - 15 } & 22.4 & 16.1 & 38.5 & 8.2 & 4.8 & 0.6 & 0.2 & 1.1 & 3.4 & 1.8 & 0.3 & 2.6 \\
\hline $15-30$ & 23.1 & 15.4 & 39.6 & 7.1 & 5.3 & 0.4 & 0.1 & 0.9 & 3.4 & 1.8 & 0.2 & 2.7 \\
\hline $30-45$ & 23.2 & 15.3 & 39.7 & 7.1 & 5.2 & 0.3 & 0.1 & 1.0 & 3.3 & 1.9 & 0.1 & 2.8 \\
\hline $45-60$ & 22.1 & 15.4 & 38.7 & 8.2 & 4.9 & 0.3 & 0.1 & 0.8 & 3.3 & 2.1 & 0.1 & 3.0 \\
\hline $60-75$ & 23.9 & 14.6 & 40.1 & 6.8 & 4.9 & 0.3 & 0.1 & 0.7 & 3.3 & 2.2 & 0.1 & 3.0 \\
\hline $75-90$ & 24.0 & 14.5 & 40.3 & 6.6 & 4.8 & 0.3 & 0.4 & 0.6 & 3.3 & 2.3 & 0.1 & 2.8 \\
\hline
\end{tabular}

Table 3: Values of Mass Attenuation Coefficient Generated by XCOM Software Program

\begin{tabular}{|l|l|l|l|l|}
\hline \multirow{2}{*}{$\begin{array}{c}\text { Soil Depth } \\
(\mathrm{cm})\end{array}$} & \multicolumn{4}{|l|}{ Energies (keV) } \\
\cline { 2 - 5 } & $\mathbf{5 9 . 5}$ & $\mathbf{6 6 1 . 7}$ & $\mathbf{1 1 7 3 . 2}$ & $\mathbf{1 3 3 2 . 5}$ \\
\cline { 2 - 5 } & \multicolumn{4}{|c|}{ Mass Attenuation Coefficient $\left(\mathrm{cm}^{2} / \mathrm{g}\right)$} \\
\hline $0-15$ & 0.1024 & 0.0382 & 0.0289 & 0.0287 \\
\hline $15-30$ & 0.1206 & 0.0394 & 0.0304 & 0.0294 \\
\hline $30-45$ & 0.1221 & 0.0386 & 0.0296 & 0.0235 \\
\hline $45-60$ & 0.1106 & 0.0364 & 0.0266 & 0.0228 \\
\hline $60-75$ & 0.1202 & 0.0422 & 0.0304 & 0.0295 \\
\hline $75-90$ & 0.1211 & 0.0411 & 0.0291 & 0.0272 \\
\hline
\end{tabular}

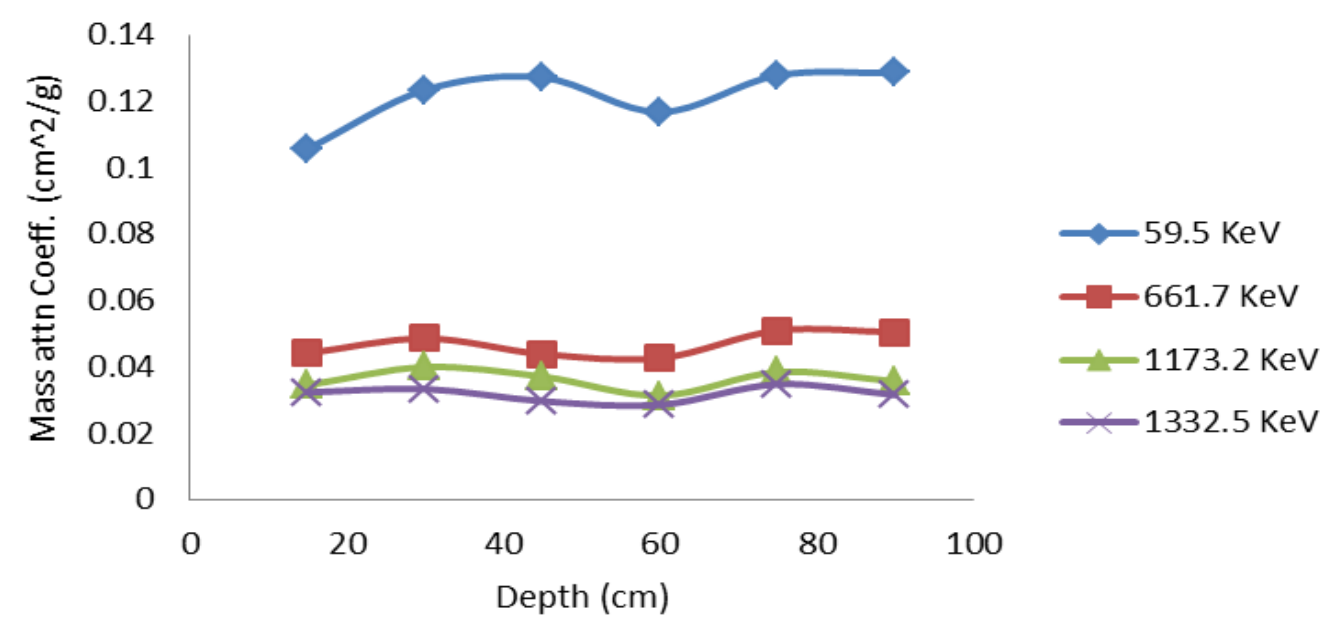

Figure 3: Mass attenuation coefficient at different depths obtained from gamma spectrometer 


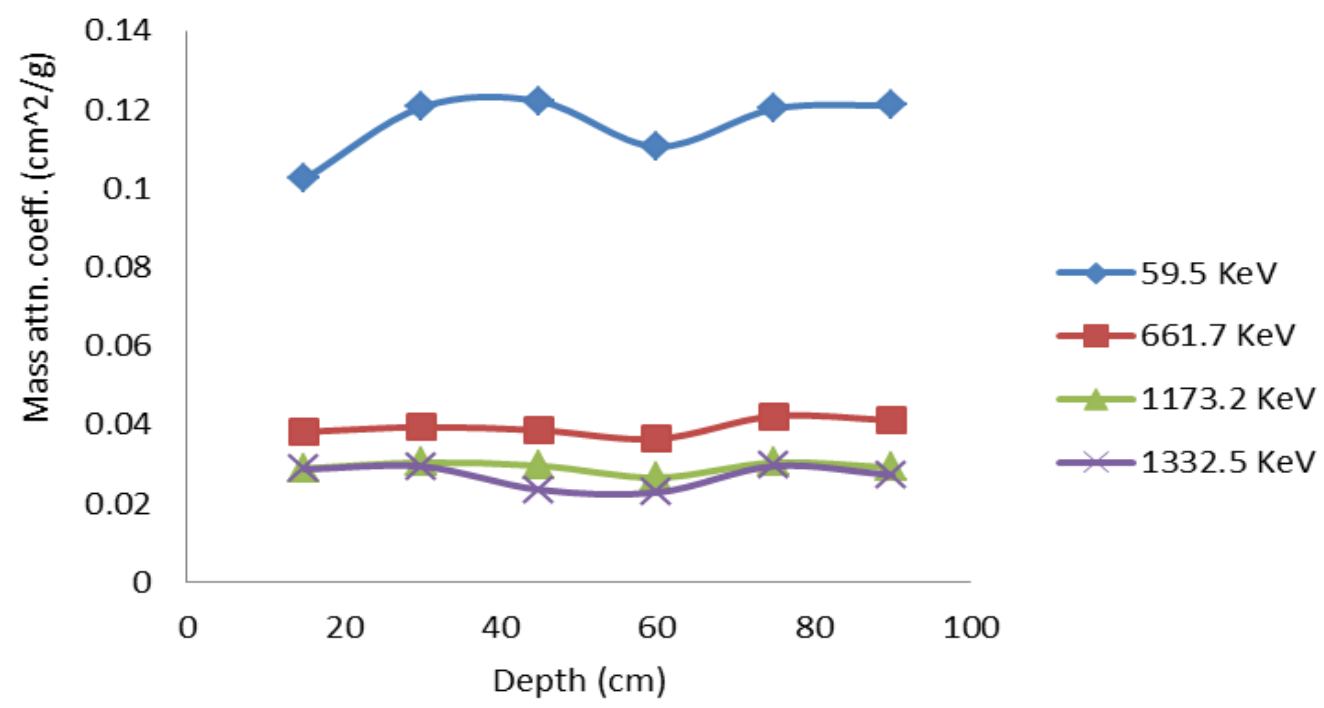

Figure 4: Mass attenuation coefficient at different depths obtained with XCOM

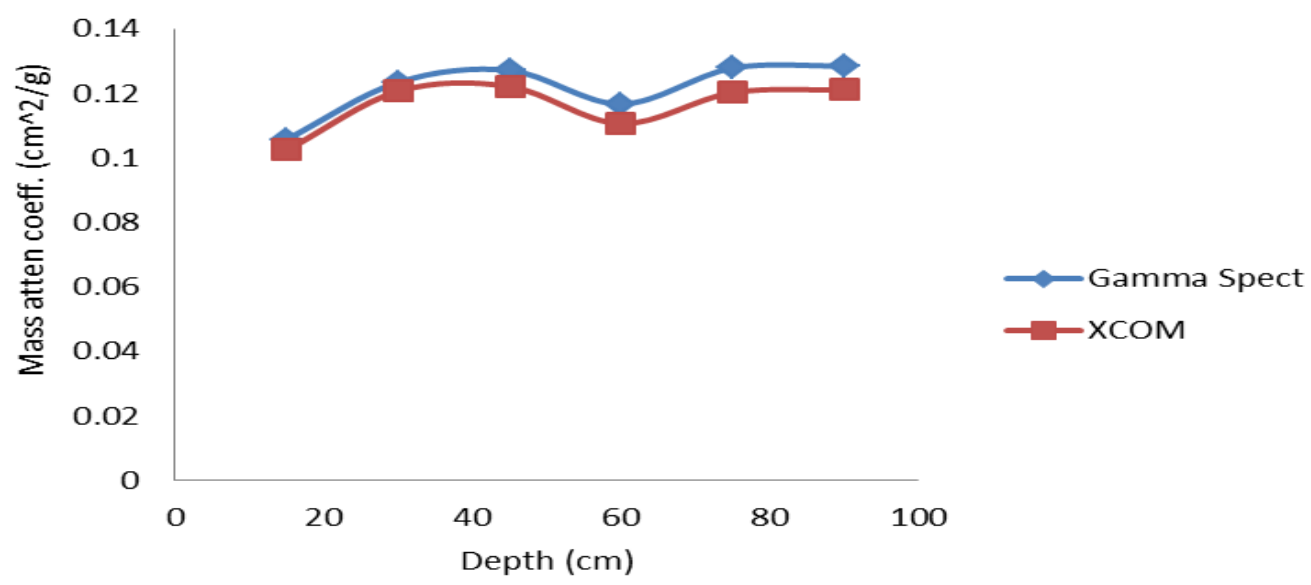

Figure 5: Comparison of Gamma spectrometry and XCOM derived $\mu_{\mathrm{s}}$ at 59.5ke

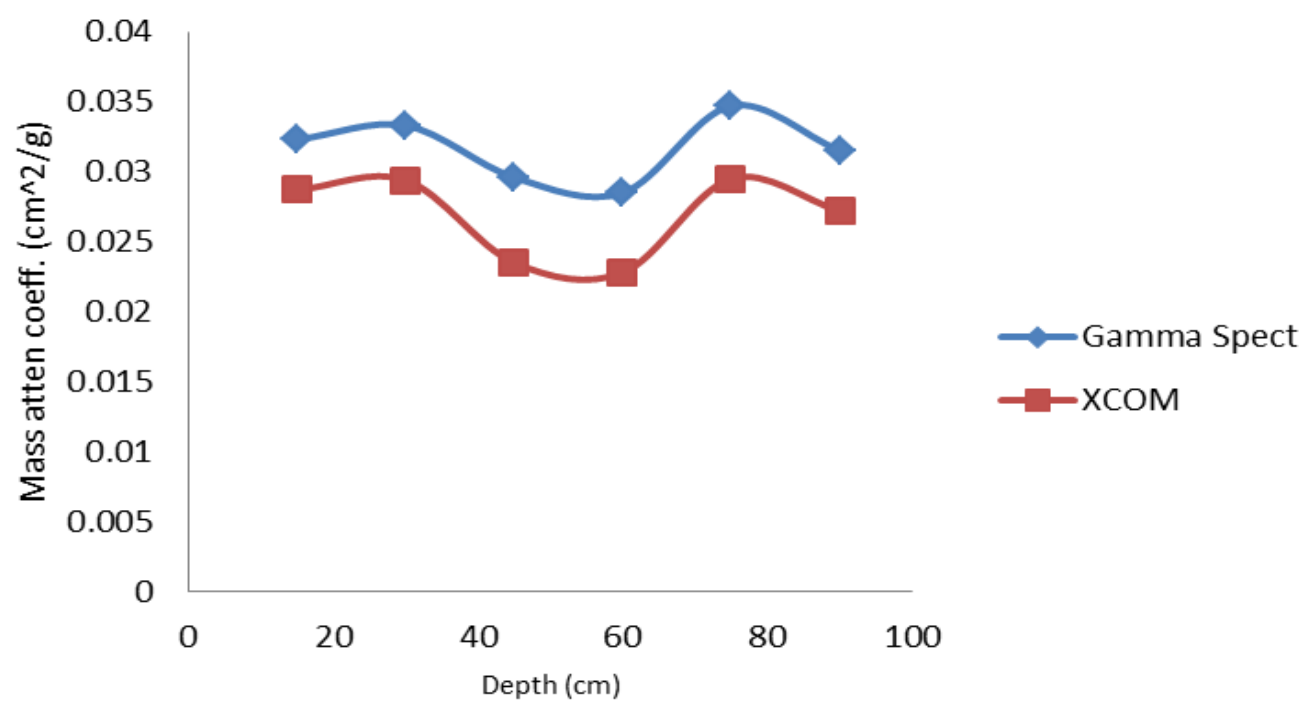

Figure 6: Comparison of Gamma spectrometry and XCOM derived $\mu_{\mathrm{s}}$ at $1332.5 \mathrm{keV}$ 


\section{Discussion}

The mass attenuation coefficients, $\mu_{s}$ obtained experimentally and that calculated using XCOM were observed to vary exponentially with photon energy as seen in figures $3-6$. The $\mu_{s}$ varies with soil depth with the highest attenuation experienced at lower energies. The Egbeda soil series, at low photon energy $(59.5 \mathrm{keV})$, shows $\mu_{s}$ increasing down the profile, reaching a maximum at $30-45 \mathrm{~cm}$ depth, drops at the 45 $-60 \mathrm{~cm}$ depth and increases at further depths down the profile. This observation correlates well with the elemental concentrations measured using the EDXRF technique. This soil series show $\mathrm{K}$ and Fe percentage concentration values which increase down the profile to the $30-45 \mathrm{~cm}$ depth, dropping at the $45-60 \mathrm{~cm}$ depth and increase at further depths down the profile. The mass attenuation coefficients obtained experimentally and that calculated using XCOM were compared, with strong correlation ranging from 0.88 - 0.96 observed between them. The little discrepancy can be attributed to the instrumental limitation imposed by the EDXRF spectrometer used for the analysis which could not measure input of silica - a major soil constituent. The fact that the constituent elements in silica (silicon and oxygen) both have atomic numbers less than 19 may account for the observed consistent lower attenuation coefficients (since the contributions of these elements to the total attenuation are not included) obtained with XCOM as compared with the respective experimentally obtained attenuation coefficients. Ajayi and Ibikunle in 2013 in their work on "Radioactivity of surface soils from Oyo state, South Western Nigeria" noted that ${ }^{40} \mathrm{~K}$ radionuclide accounted for the largest contribution to the total specific activity concentration in soil samples from southwest Nigeria, and attributed this fact to the soil parent Precambrian metamorphic rock underlying the territory and the use of phosphate fertilizer by farmers in the areas.

The variation in the mass attenuation coefficient can be linked to the variation in the soil total porosity because the more compacted the soil, the more the gamma photons, through interaction, surfer attenuation (Pires, et. al., 2006). It can therefore be concluded that the consistently lower mass attenuation coefficient observed at the $45-60 \mathrm{~cm}$ depth at the varying energy values could indicate higher porosity thus allowing for greater drainage of water. This could account for why the Egbeda soil series did not offer a good yield for cassava as experienced by the farmers in southwestern Nigeria. Moreover, a look at the percentage concentration of elements in table 2 shows a reduction in the $\mathrm{K}, \mathrm{Fe}, \mathrm{Mn}$ and $\mathrm{Zn}$ values at the $45-60 \mathrm{~cm}$ depth which are critical elements needed for plant growth (Njinga, et. al., 2013). Addition of organic matter or a nutrient binding substrate to the $45-60 \mathrm{~cm}$ depth is strongly recommended in order to improve the productivity of the Egbeda soil series in southwest Nigeria.

\section{Conclusion}

This work had succeeded in providing useful information on the mass attenuation coefficient values at varying photon energies and elemental concentration at different depths into the soil profile for the Egbeda soil series of southwest Nigeria. This information on the mass attenuation coefficients, elemental composition, and concentrations at varying depths into the soil profile will go a long way in contributing to efforts at improving the soil condition of the Egbeda soil series.

\section{ORCID}

Adejumo, O.O http://orcid.org/0000-0003-0147-5756

Fajemiroye, J.A. http://orcid.org/ 0000-0002-4424-810X

\section{References}

[1] Abegunde LO, Shaba HA, Alaga AT, Adebayo GO, Abiola M (2017) Profitability of cassava/maize on Iwo and Egbeda soil series in Oyo State, Nigeria. Canadian Journal of Tropical Geography 4(2): 1 - 10, URL: http://laurentian.ca/cjtg.

[2] Adejumo OO (2009) Soil Bulk Density and Water Content Measurements of Southwestern Nigerian Soils by Dual Energy Gamma-Ray Transmission Method. PhD's Thesis, Nigeria: Obafemi Awolowo University, Ile-Ife.

[3] Ajayi OS, Ibikunle SB (2013) Radioactivity of Surface Soils from Oyo State, Southwestern Nigerian. International Journal of Radiation Research 11(4): 271 - 278, 
https://search.proquest.com/openview/70a9cffcf40d8b84f8711dc7dcda6d0c/1?pq-

origsite $=$ gscholar\&cbl=105760.

[4] Hillel D (1998) Environmental Soil Physics, California: Academic Press, San Diego. ISBN13:978-0-12-348525-0.

[5] Knoll GF (2000) Radiation Detection and Measurement, $3^{\text {rd }}$ ed. New York: John Wiley \& Sons.

[6] Njinga RL, Moyo MN, Abdulmaliq SY (2013) Analysis of essential elements for plants growth using instrumental neutron activation analysis. International Journal of Agronomy 1-9. https://doi.org/10.1155/2013/156520

[7] Nordin I (1999) Natural Activities of ${ }^{238} \mathrm{U},{ }^{232} \mathrm{Th}$ and ${ }^{40} \mathrm{~K}$ in building materials. Journal of Environmental Radioactivity 43: 255 -258. https://doi.org/10.1016/S0265-931X(98)00033-2

[8] Pires L, Bacchi O, Dias N (2006) Gamma-ray beam attenuation to assess the influence of soil $\begin{array}{llll}\text { texture on } \quad \text { structure } & \text { deformation. Nukleonika 51(2): }\end{array}$ http://yadda.icm.edu.pl/baztech/element/bwmeta1.element.baztech-article-BUJ6-0004-0018

[9] Pourimani R, Mohebian M, Modarresi SM (2020) Assessment of the Soil Self Attenuation Correction Factor to Determine the Efficiency of a High-Purity Germanium Detector. IraniaJournal of Science and Technology, Transactions A: Science 44(1): 311-317. https://doi.org/10.1007/s40995-020-00816-4

[10]Smith AJ, Montgomery RF (1962) Soil and Land Use in Central Western Nigeria. Government Printer, Ibadan, Western Nigeria. 